\title{
Elección informada, niños sordos y sus familias -- ideas básicas y desarrollo de proyectos.
}

\begin{abstract}
Alys Young ${ }^{1}$, Ros Hunt ${ }^{1}$, Gwen Carr $^{2}$, Anne-Marie Hall ${ }^{2}$, Wendy McCracken ${ }^{3}$, Amy Skipp $^{2}$, Helen Tattersall ${ }^{1}$.
\end{abstract}

${ }^{1}$ Universidad de Manchester, School of Nursing, Midwifery and Social Work.

${ }^{2}$ National Deaf Children's Society, UK.

${ }^{3}$ Universidad de Manchester, Audiology and Deafness Group

Reino Unido 


\section{Resumen}

Este artículo trata los temas de elección informada (informed choice) y la oferta de servicios para niños sordos y sus familias. En primer lugar, describe en líneas generales el trasfondo de por qué la elección informada ha llegado a ser una cuestión de tanta importancia en el contexto inglés. A continuación describe las primeras fases de un proyecto de investigación y desarrollo, diseñado para orientar tanto a profesionales como a los padres en un planteamiento de elección informada. Estas fases constan de una revisión detallada de la literatura y una serie de consultas con distintos proveedores de servicios profesionales y padres de niños sordos. Se presentan quince principios clave que se han derivado de estas fases de recogida de datos. Con ellos se fundamenta nuestra comprensión de las complejidades en lo que constituye la elección informada. Se aportan también ejemplos verídicos del documento de orientación profesional y del manual para padres. Éstos sirven para subrayar las dificultades que se encuentran a la hora de transformar estas cuestiones fundamentales en documentos prácticos y útiles, tanto para padres como para profesionales.

Keywords: niños sordos; elección informada 